\title{
How do Hearing Aid Owners Acquire Hearing Aid Management Skills?
}

DOI: $10.3766 /$ jaaa.17129

\author{
Rebecca J. Bennett*† \\ Carly J. Meyer \\ Robert H. Eikelboom*†§
}

\begin{abstract}
Background: Clinical studies have found up to $90 \%$ of hearing aid owners demonstrate difficulty with basic hearing aid management tasks and almost $50 \%$ of hearing aid owners self-report not receiving enough practical help from their clinician regarding how to use their hearing aid. Although studies have highlighted the overwhelming amount of information and training required to learn how to use a hearing aid appropriately, a gap remains in the literature regarding the range of methods by which hearing aid owners acquire the knowledge and skills for hearing aid use, and whether these approaches are considered beneficial.
\end{abstract}

Purpose: To gain insight into how both hearing aid owners and hearing health clinicians view the acquisition of hearing aid management skills and the efficacy of currently used methods of hearing aid training.

Research Design: Concept mapping techniques were used to identify key themes, wherein participants generated, sorted, and rated the importance of statements in response to the question "How do hearing aid owners learn the skills required to use, handle, manage, maintain, and care for their hearing aids?"

Study Sample: Twenty-four hearing aid owners (aged 56-91 years; 54.2\% male) and 22 clinicians (aged 32-69 years; 9.1\% male).

Data collection and Analysis: Participant perspectives were collected via group concept mapping sessions in October 2015. Hierarchical cluster analysis was used to identify themes and develop a framework for understanding how skill acquisition occurs. Participants rated each method of hearing aid skill acquisition as to how beneficial it was and how often it was used.

Results: Participants identified 75 unique items describing how hearing aid management skills are acquired within six concepts: (1) Relationship with the clinician, (2) clinician as a source of knowledge and support, (3) hands-on experience, (4) seeking additional information, (5) asking support people for help, and (6) external resources.

Conclusions: The results of this study highlight the diverse methods and sources by which hearing aid owners learn the skills necessary to use, manage, and maintain their hearing aids. Significant emphasis was placed on the role of the hearing health clinician to provide training, support, and an ongoing professional relationship, with lesser roles played by family, friends, and other health professionals.

Key Words: hearing aid, hearing aid management, mixed methods, outcomes

Abbreviation: $\mathrm{SD}=$ standard deviation

*Ear Science Institute Australia, Subiaco, Australia; †Ear Sciences Centre, The University of Western Australia, Nedlands, Australia; $\neq$ School of Health and Rehabilitation Sciences, University of Queensland, St. Lucia, Australia; §Department of Speech-Language Pathology and Audiology, University of Pretoria, Pretoria, South Africa org.au

Corresponding author: Rebecca J. Bennett, Ear Science Institute Australia, Subiaco 6008, Western Australia, Australia; Email: bec.bennett@earscience.

This study was supported by Unitron Australia and the Ear Science Institute Australia. Rebecca Bennett was supported by an Australian Government Research Training Program (RTP) Scholarship. 


\section{INTRODUCTION}

$\mathrm{H}$ earing loss is a common chronic health problem (Solheim et al, 2011), most often managed with hearing aids (Chisolm et al, 2007). Although it is recommended that hearing health-care clinicians provide training on hearing aid handling and maintenance as part of the rehabilitation program (Audiology Australia, 2013; American Speech-LanguageHearing Association, 2015), clinical studies suggest that the level of handling skills demonstrated by hearing aid owners is low (Upfold et al, 1990; Bertoli et al, 2009; Ferrari et al, 2015; Bennett et al, 2017a). This is concerning, as poor hearing aid handling skills have been found to be associated with low hearing aid benefit (Campos et al, 2014) and reduced satisfaction with hearing aids (Kumar et al, 2000; Campos et al, 2014).

Currently, clinicians may spend approximately 45 minutes instructing individuals on hearing aid management across an average of two to five appointments throughout the 30-45-day rehabilitation program (or trial period) (Kochkin et al, 2010; Bennett et al, 2016). Although this will vary across settings and countries, the general nature of training that is delivered is during these face-to-face appointments is verbal and may be supplemented with written or digital materials. However, despite there being recent developments in digital materials to aid hearing aid management (for example, Ferguson et al, 2015), the documented use of written and digital materials is currently low (Kochkin et al, 2010). In addition, although this may be the common process followed, not all clients receive optimal access to audiological care because of rural access or funding restrictions. Furthermore, given the time constraints clinicians experience while delivering the large amount of information and training associated with hearing aid use, it is possible that they do not always provide all of the necessary information and training required (Bennett et al, 2018b).

A study by Kelly et al (2013) found that $40 \%$ of older hearing aid owners reported low confidence in managing their hearing aids, attributing their lack of confidence to insufficient provision of information and training during the rehabilitation program and in the months and years that followed. Information transfer in the audiology setting has been described as "information dumping" (English, 2008), with hearing aid owners unable to recall approximately $25-65 \%$ of hearing aid management information four weeks after it was provided (Reese and Hnath-Chisolm, 2005; El-Molla et al, 2012). This ineffective exchange of information may contribute to the high rates of hearing aid management difficulty (Campos et al, 2014; Bennett et al, 2017a). Arguably, the current methods for hearing aid management skill training are insufficient. It has been suggested that clinicians underestimate the amount of information patients want (LaplanteLévesque et al, 2010a), have little understanding of patient health literacy (Nair and Cienkowski, 2010; Brooke et al, 2012), and "dump" information on their patients (English, 2008) rather than provide a meaningful exchange (Grenness et al, 2014).

An adjunct study to the one reported here used a group concept mapping approach with 24 hearing aid owners and 22 clinicians to investigate what hearing aid owners must do to use, handle, manage, maintain, and care for their hearing aids (Bennett et al, 2018b). Participants identified 111 unique items across six concepts (daily hearing aid use, hearing aid maintenance and repairs, learning to come to terms with hearing aids, communication strategies, working with your clinician and advanced hearing aid knowledge), highlighting the overwhelming amount of information and training hearing aid owners need to acquire. However, a gap remains in the literature regarding the range of methods by which hearing aid owners acquire the knowledge and skills for hearing aid use, and whether these approaches are considered beneficial. Investigating the currently used methods of knowledge and skill acquisition used by hearing aid owners may elucidate flaws in current methods of service delivery and opportunities for improvement. Accordingly, the purpose of this study was to gain insight into how both hearing aid owners and clinicians view the acquisition of hearing aid management skills and the effectiveness of currently used methods of hearing aid training.

\section{METHODS}

$\boldsymbol{T}$ his study forms the second part of a larger project 1 on the acquisition of hearing aid management skills. Both studies used the same methodology and participant groups to address two different research questions. Where the first study investigated what hearing aid owners must learn to use, manage, and care for their hearing aids (Bennett et al, 2018b), this second study describes how those skills and knowledge are acquired. Both studies used group concept mapping, a segmentation methods approach that uses qualitative and quantitative techniques for data collection and analysis (in this case, multidimensional scaling and hierarchical cluster analysis) (Trochim, 1989). Wedel and Kamakura (2000) classify segmentation methods according to whether they are an a priori method (where segments are determined by the research in advance) or a post hoc method (where data analysis determines the number and type of segments (Lilien and Rangaswamy, 2004). This study on acquisition of hearing aid management skills used the latter. Participants attended two data collection sessions. The first session was a focus group, wherein participants put forward statements describing their thoughts, perceptions, and experiences 
about each of the research questions (brainstorming session). During the second session, participants gave meaning to these statements through individual grouping and rating activities.

The literature on concept mapping does not specify a minimum number of participants for the brainstorming activity, although Trochim (1989) recommends groups of 10-20 people to ensure a variety of opinions and still enable group discussion. Participants should be diverse and represent all stakeholders involved in a topic, in this case, both hearing aid owners and clinicians. Participation can be (a) in a group session, which is preferred as interaction promotes the generation of statements, (b) individually with the researcher, or (c) individually online where the participant can see statements that have already been generated. The minimum number of participants recommended for the grouping activity is 15 , as studies with fewer than 15 participants are more likely to generate less reliable concept maps (indicated by the stress value; described in detail in the following paragraphs) (Rosas and Kane, 2012). There is no recommendation in the literature regarding a minimum number of participants for the rating activity; however, larger numbers would be required for generalizability to the wider population.

\section{Participants}

Hearing aid owners were recruited via email or post through two participating clinics in Perth and Brisbane, Australia, and via the Communication Research Registry (a database of people who have expressed an interest in being involved in research). All adult hearing aid owners were invited to participate with no exclusions placed on participants. All clinicians on a hearing aid manufacturers' database of Australian clientele were invited to participate via email. Purposive sampling was used to ensure that participants included both hearing aid owners and clinicians, with representation of both genders, a range of ages, and a range of experience using/fitting hearing aids. The initial group of respondents was sufficiently diverse and so no further recruitment was required beyond that described previously.

The hearing aid owner group $(\mathrm{n}=24)$ included persons aged between 56 and 91 years (mean $=78 ; \mathrm{SD}=9$ ), with more males $(\mathrm{n}=15)$ than females $(\mathrm{n}=9)$. The clinician group $(n=22)$ included persons aged between 32 and 69 years $($ mean $=43 ; \mathrm{SD}=10)$; of which two were male and 20 were female. A range of experience with hearing aids was reported by hearing aid owners (owning hearing aids for less than one year $[\mathrm{n}=2], 1-5$ years $[\mathrm{n}=7], 5-10$ years $[\mathrm{n}=8]$, and more than ten years $(\mathrm{n}=$ 3]). Similarly, clinicians reported a range of experience fitting hearing aids (less than five years [n $=3], 5-10$ years $[\mathrm{n}=2], 10-20$ years $[\mathrm{n}=16]$, and $>20$ years $[n=1])$. The hearing aid owners were based in the Australian states of Western Australia $(\mathrm{n}=17)$ and Queensland $(\mathrm{n}=7)$, and were fitted with hearing aids from seven different manufacturers. The participating clinicians were based in Queensland $(\mathrm{n}=3)$, Victoria $(\mathrm{n}=1)$, Tasmania $(\mathrm{n}=1)$, and Western Australia $(\mathrm{n}=17)$, and worked in a range of different clinical environments.

\section{Procedure}

Ethical approval for this study was granted by the Human Research Ethics Office of The University of Western Australia and The University of Queensland's Behavioural and Social Sciences Ethical Review Committee. All participants provided informed consent to participate.

Participants were required to attend two data collection sessions; the first included a brainstorming activity and the second included two tasks: a grouping and a rating task (described in the following paragraphs). Data collection was face-to-face for participating hearing aid owners and took place in two sites (Perth and Brisbane). Data collection occurred via an online portal for participating clinicians (version 4; Concept Systems Incorporated, 2011, Ithica, NY). The sessions were conducted in October and November 2015.

\section{Brainstorming}

There were three separate brainstorming sessions, one for each of the Brisbane and Perth hearing aid owner sub-cohorts and one for the clinician group. For hearing aid owners, this session was split into two 45-minute periods with a 15 -minute break inbetween. Participants were first asked to generate statements that described "What hearing aid owners must do in order to use, handle, manage, maintain, and care for their hearing aids appropriately" (see Bennett et al, 2018b). During the second period, participants were asked to generate statements that described "How hearing aid owners learn the skills required to use, handle, manage, maintain, and care for their hearing aids." Statements put forward by participants were entered into a Microsoft Excel spreadsheet and projected on a screen as they were generated for all to see, allowing participants to build on each other's statements. Participant instructions were delivered in a neutral tone and participants were not prompted. Clarification was requested if the participant's statement was not clear. The research team accepted all statements during the brainstorming activity so as not to deter contributions. All members of the group were given equal opportunity to provide input.

For the clinician group, the brainstorming session took place via the online portal available in the concept 
mapping software Concept Systems (version 4; Concept Systems Incorporated, 2011). The clinicians were asked to generate statements in response to the same two research questions that were used by the hearing aid owner group. Participating clinicians were able to view each other's de-identified statements; in this way, clinicians could enter new statements that built on existing statements or enter completely new statements. Clinicians and hearing aid owners were not able to see the statements put forward by the other cohort at this stage.

Following the brainstorming session, the research team pooled and refined all of the statements from all three groups (hearing aid owner Perth and Brisbane group, and clinician group). Consolidating and editing of the brainstormed statements was performed by two members of the research team (R.J.B. and C.M.) and cross-checked by a third (R.H.E.). Repeated statements and those that the research team agreed irrelevant to describe how the skills are learned were omitted (Poost-Foroosh et al, 2011). For example, "manufacturers and clinics are reducing their own costs." Similar brainstormed ideas were combined; for instance, "prioritise and give only basic instructions at first," with "keep instructions simple and minimal (prioritise), particularly if client seems overwhelmed" and "the magnitude of information/instructions provided is overwhelming and it can be easier to focus only on the basic and necessary instructions at first" were combined to become statement 40: "prioritising the magnitude of information/instructions provided and only focusing on the basic and necessary instructions at first." Some statements were reworded for clarity, such as "start younger-easier to learn" that was reworded to become statement 6: starting at a younger age, that is, it is easier to learn new things when you are younger. All of the statements were reworded in a way to ensure they were not presented in the first person and thus could be used by both hearing aid owners and clinicians for the grouping and rating activities. The resulting set of statements served as the core content for the two grouping and rating tasks.

\section{Grouping and Rating of the Statements}

During the second session participants were instructed to group the statements in a way that made sense to them, ensuring that (a) each statement was only placed in one group; (b) they were to create at least five groups (although not all did); (c) a statement could be put in its own group if it is unrelated to the other statements or if it stood alone as a unique statement; and (d) they were not to have a "miscellaneous" or "other" groups. Participants were informed that there was no right or wrong way to group the statements. Participants were then asked to provide titles that encapsulated each group.
For the rating task, participants were given the list of the statements and were asked to rate each statement based on the extent hearing aid owners currently use each mode of training/learning identified, using a five-point Likert scale $(1=$ never to $5=$ always $)$. Participants were also asked to rate how beneficial each of the training/learning techniques identified would be to successful hearing aid handling and maintenance using a f-point Likert scale $(1=$ minimally beneficial to $5=$ extremely beneficial).

The hearing aid owners undertook the grouping and rating tasks via face-to-face group sessions (Brisbane and Perth). Two hours were allocated for the session, although many finished the tasks early and were free to leave. The statements were printed on individual cards and participants asked to sort the cards into groups based on how similar in meaning they were to one another. For the rating task, hearing aid owners were provided with a printed list of the statements and asked to rate them as described previously. Although hearing aid owners attended this session as a group, participants were instructed to work independently. Clinicians undertook the grouping and rating tasks via the online portal (version 4; Concept Systems Incorporated, 2011), wherein clinicians logged in and completed the tasks at any time within a six-week period. For a detailed description of how these tasks are performed within the software, see Bennett et al (2018a).

All participants attended the brainstorming sessions and contributed to the generation of statements for both research questions (a) identification of what hearing aid owners must learn to use and manage their hearing aids and (b) how this knowledge and skill is acquired. The participants were then randomly allocated into two groups using a random number generator in Microsoft Excel and assigned to one of the two research questions for the second session grouping and rating tasks. This was carried ou to reduce the time required for the second data collection session (estimated to be two hours if tasks for the completion of one research question and four hours if tasks for both research questions had to be completed). All participants were invited to complete grouping and rating for both research questions and directed to start with the question for which they were randomly allocated to. Of the 24 hearing aid owners who participated in the brainstorming session, 11 completed the grouping activity (11 of the 12 allocated to this research question; one did not attend the second session) and 17 completed the rating activity (including 11 of the 12 allocated to this question and six of those allocated to the other research question). Twenty-two clinicians participated in the brainstorming session, ten of whom completed the grouping activity (ten of the 11 allocated; one did not participate) and 11 completed the rating activity (the 11 allocated to this research question). 


\section{Data Analysis and Interpretation}

Concept Systems (version 4; Concept Systems Incorporated, 2011) software was used for data analysis. The participants' grouping and rating data were coded as coming from a hearing aid owner or a clinician.

Multidimensional scaling was used to generate a point map to graphically display the relationship between statements as indicated by the sorting task. Each point on the map represents one brainstormed statement, with the proximity of two points indicating how often these statements were grouped together by participants; the smaller the distance between two points, the more often participants grouped the two statements together. The strength of the multidimensional scaling analysis was tested by computing a stress index. The stress index indicates the goodness of fit of the two dimensional configuration to the grouping data. For concept mapping studies, a stress value lower than 0.35 is recommended (Kane and Trochim, 2007). Hierarchical cluster analysis was used to determine the key concepts generated by the participants, based on a consensus of how the participants grouped the individual statements. For a more detailed description on how multidimensional scaling analysis and hierarchical cluster analysis were used to generate the concept maps see Bennett et al (2018a).

After examining possible cluster solutions, two of the authors (R.J.B. and C.M.) came to a decision about the best number of clusters to represent the content of the map and the grouping data, cross-checked by a third (R.E.). This decision was informed by reviewing the statements within each cluster and discussing whether the merging or splitting of clusters was appropriate; that is, it made sense given the statements in that particular cluster (Jackson and Trochim, 2002). These decisions were also informed by bridging scores, indicating how often participants grouped statements in this way. The lower the bridging score for a particular cluster, the more often participants grouped these statements together. Conversely, a higher bridging score indicated that participants were less likely to have grouped these statements together, and thus, the cluster may have benefited from being split into two clusters. As there are no minimum bridging scores or threshold values indicated in the literature, the authors considered each concept's bridging score before determining whether splitting the cluster and reallocating the statements between the new clusters made sense. It is important to note here that the researchers only determined the number of clusters; the hierarchical cluster tree structure is entirely determined by the grouping data put forward by participants (Jackson and Trochim, 2002). The resulting map is the concept map. Each cluster represents a key concept and was given a name based on the grouping labels designated by the participants during data collection. The research team generated a description of each concept identified by the concept map based on the statements it contained and the labels indicated by the participants.

A concept map was generated for each cohort (hearing aid owners and clinicians). To determine whether the cohort concept maps differed significantly a splithalf reliability measure (comparing the data from each cohort) was calculated using the concept mapping software (version 4; Concept Systems Incorporated, 2011) and Spearman-Brown Prophecy Formula correction applied using IBM SPSS Statistics (version 21.0; IBM Corp., Armonk, NY). A correlation $>0.7$ was considered high (Hinkle et al, 2003) and indicated sufficient consensus across participants, that is, that the concept maps generated by each cohort were similar enough to be combined.

A similar reliability analysis was conducted of the final concept map (hearing aid owner and clinician data combined). The participant cohort was randomly split into two sub-cohorts, and then separate similarity matrices and cluster maps were generated for each (based on the number of clusters selected for the final map) (Trochim, 1993). Correlation between the two maps was again evaluated by applying the Spearman-Brown correction correlation to the split-half correlation (Trochim, 1993) using IBM SPSS Statistics (version 21.0; IBM Corp.). A correlation $>0.7$ was considered high (Hinkle et al, 2003), indicating that the cohort map accurately represented the participants' grouping data.

To validate the interpretation of the data, the final concept map generated was sent to all participants (hearing aid owners and clinicians) for feedback. Participants were asked to reflect on whether (a) the concept map accurately represented the concepts informed by the statements, (b) the name of each of the concepts accurately represented the statements it contained, and (c) the description of each of the concepts accurately represented the statements it contained. Participant feedback informed whether the concept map(s) needed to be redefined or labeled and described differently.

The participants' rating scores were used to calculate mean ratings for each concept. Reliability estimates of the ratings data were calculated using Cronbach's alpha to determine internal consistency (Rosas and Kane, 2012). Cohort comparisons were made using a pattern matching graph, a ladder graph that compares average cluster ratings between two variables (in this case sub cohorts: hearing aid owners and clinicians), based on the cluster map selected and the participants rating data. Welch's t test was used to compare the mean cluster ratings between cohorts. A scatterplot was used to plot the individual statements according to participant rating scores (currently used against beneficial). This facilitated identification of the hearing aid training techniques (individual statements) that were deemed 
to be (a) currently used but not beneficial, (b) currently used and beneficial, (c) not currently used despite being beneficial, and (d) not currently used and not beneficial.

\section{RESULTS}

B rainstorming sessions yielded 136 statements across all three sessions describing how hearing aid owners acquire the knowledge and skills to use, handle, manage, maintain, and care for their hearing aid(s). Editing the statements resulted in a final list of 75 statements used in the grouping and rating tasks (Appendix).

The concepts identified through cluster map generation for the hearing aid owner group and the clinician group did not differ greatly (the split-half correlation was 0.75 and the Spearman-Brown correction correlation was 0.86 ), and as such a combined cluster map was generated and used for the remainder of the analyses. The final cluster map selected had a stress index of 0.22 , suggesting that the cluster map was a good representation of the grouping data (Trochim, 1993). Reliability testing achieved a split-half correlation of 0.85 and Spearman-Brown correction correlation of 0.92 , suggesting that the concept map accurately represented the grouping data (Trochim, 1993).

The concept map revealed six concepts: (a) Relationship with the clinician, (b) clinician as a source of knowledge and support, (c) hands-on experience, (d) seeking additional information, (e) asking support people for help, and (f) external resources (Figure 1). The bridging score for each concept (Figure 1) indicates how similar the statements within the concept were to each other. The concepts "relationship with the clinician" and "clinician as a source of knowledge and support" had smaller bridging scores ( 0.14 and 0.18 , respectively) than the other pairs of concepts, indicating that participants more often agreed that the statements within each of these two concepts were similar or related. The bridging scores for the other four concepts ranged from 0.49 to 0.62 , suggesting that participants less often agreed as to which group (concept) the statements belonged.

Table 1 provides a description of each concept and example statements. The concept "relationship with the clinician" describes understanding the importance of trust and two-way communication in developing a therapeutic relationship with the client, as well as the delivery of individualized care through an understanding of the patient's overall health and involvement in decisions. "Clinician as a source of knowledge and support" describes the role of the clinician in providing information, training and ongoing support. "Hands-on experience" describes the hearing aid owner as being selfdriven to master hearing aid management, specifically through motivation and perseverance. "Seeking additional information" describes actively seeking additional information and training through asking questions, reading supplementary material, practicing physical tasks, and committing to learning the necessary skills. "Asking support people for help" describes sourcing information from others to acquire the skills to manage hearing aids or relying on others to perform tasks. "External resources" describes accessing information

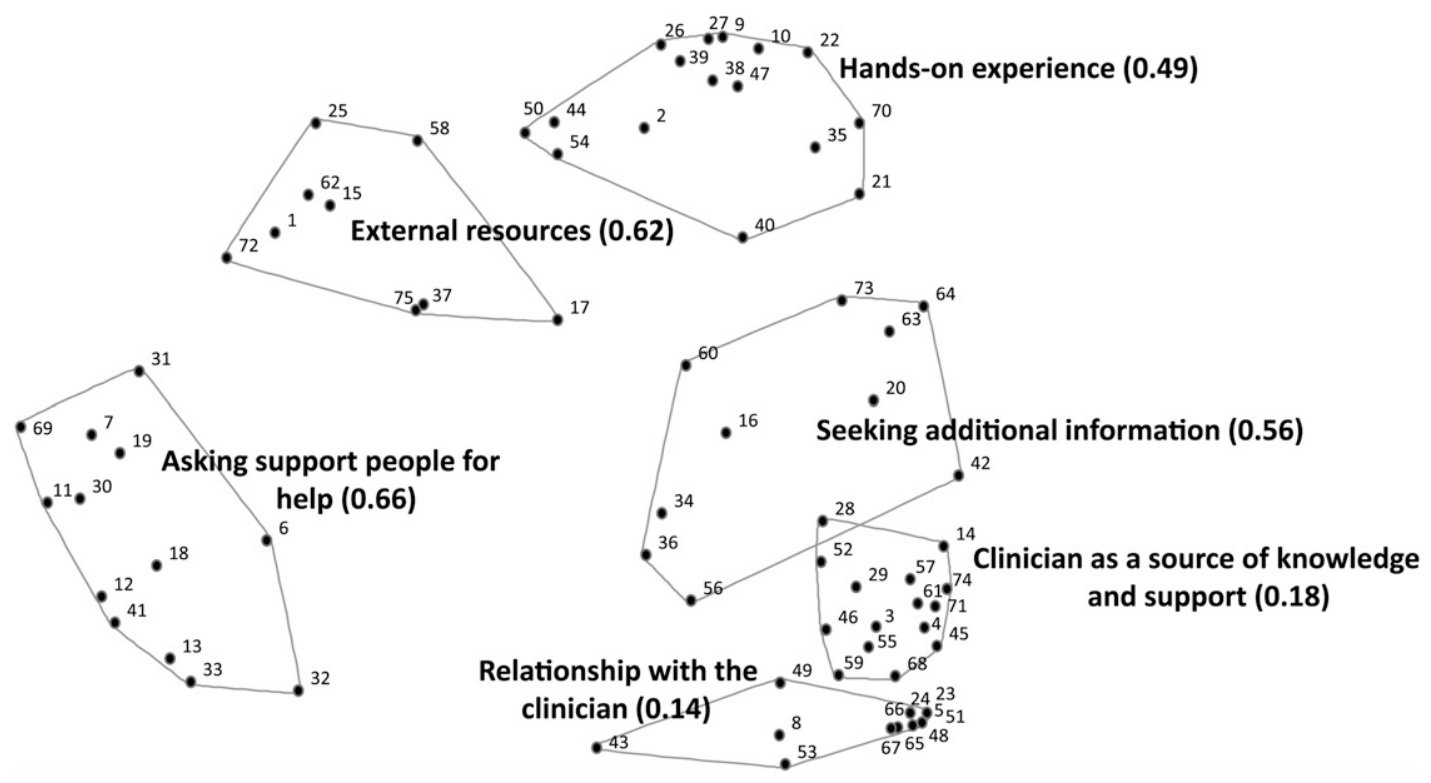

Figure 1. Concept map of the six concepts describing how hearing aid management skills are acquired. The smaller numbers refer to the individual statements generated by participants and listed in the Appendix. The bridging scores for each concept (shown in parentheses) indicate how often participants grouped these statements together, with a lower score indicating that participants more often grouped these statements together. 
Journal of the American Academy of Audiology/Volume 30, Number 6, 2019

Table 1. Six Concepts Describing How Hearing Aid Owners Learn the Skills Necessary to Use and Manage Their Hearing Aids

\begin{tabular}{|c|c|}
\hline Concepts & Concept Description \\
\hline $\begin{array}{l}\text { Relationship with the } \\
\text { clinician }\end{array}$ & $\begin{array}{l}\text { Understanding the importance of trust and } \\
\text { two-way communication in developing a } \\
\text { therapeutic relationship with the client. } \\
\text { Individualized care through an } \\
\text { understanding of the patients overall } \\
\text { health and involvement in decisions. }\end{array}$ \\
\hline
\end{tabular}

Clinician as a source of The role of the clinician in providing knowledge and support information, training, and ongoing support.

Hands-on experience

Self-driven to master hearing aid management, specifically through motivation and perseverance.

\section{Seeking additional information}

\section{Asking support} people for help
Actively seeking additional information and training through asking questions, reading supplementary material, practicing practical tasks and committing to learning the necessary skills.

Sourcing information from others to acquire the skills to manage hearing aids or relying on others to perform tasks on their behalf.
Example Statements

51. Having a good relationship with their clinician, especially open lines of communication to be able to ask for support (0.00)

23. With encouragement from their clinician (0.01)

48. Being made to feel like an important part of the rehabilitation (hearing aid fitting) process, where the clinician makes it clear that the hearing aid owner is welcome to ask questions and take their time (0.01)

68. Knowing that they have someone to go to with questions, that is, the clinician (0.05)

4. Going back to their clinician and asking more questions (0.12)

29. Asking the clinician how to perform certain tasks, for example, how to change the speaker/wax filter (0.18)

46. Attending several appointments over the fitting process rather than one large appointment, as too much information in one chunk can be difficult to remember (0.22)

14. Asking their clinician to summarise the important tasks on a cheat sheet, that is, a simple overview of the more common hearing aid instructions (0.29)

39. Making time to practice at home while in a relaxed environment (0.41)

9. Through practical experience, just trying things themselves when problems arise (0.42)

50. Using troubleshooting guides, as it can be both helpful and empowering to be able to solve their own problems $(0.47)$

40. Prioritising the magnitude of information/instructions provided and only focusing on the basic and necessary instructions at first $(0.60)$

70. Trying new things if they can't do the things the clinician has instructed, for example, different ways to insert the hearing aid (0.61)

34. Repeatedly asking questions until they get an answer that makes sense to them (0.52)

16. Asking for printouts of the information (0.53)

56. Engaging in an ongoing rehabilitation program that allows them to gradually build upon their skills in a supportive and timely manner, where appointments are scheduled to meet their personal needs (0.44)

11. Asking nursing staff (both in general hospitals and care facilities), although they usually don't know how to help (0.43)

12. Asking family members to do it for them (0.55)

41. Asking partners and/or family members to attend appointments (0.56)

19. Asking their General Practitioner (family doctor) (0.58)

7. Asking friends with hearing aids how they do things (0.59)

13. Getting family members to come to appointments so that they can learn how to assist (0.69) 
Table 1. Continued

\begin{tabular}{lcc}
\hline Concepts & \multicolumn{1}{c}{ Concept Description } & Example Statements \\
\hline External resources & Accessing information through mediums & 17. Through the quarterly/annual clinic newsletters they \\
& receive offering tips/information on hearing and hearing \\
& aids $(0.54)$ the rehabilitation program. & 58 . Viewing videos that demonstrate/explain the different \\
& skills they need to use hearing aids, available on some \\
& clinic websites (0.55) \\
& 15. Going to the library and borrowing a book on hearing aid \\
& selection, use, and management $(0.59)$
\end{tabular}

Note: The perspectives of hearing aid owners and clinicians are combined. Bridging scores are indicated in parentheses for each statement, smaller bridging scores indicate that participants were more likely to place this statement in this concept.

through media external to the clinic or clinician. The example statements included in Table 1 are those with lower bridging scores, that is, those statements that were most often placed in this concept by the participants. Thus, it is likely that they best represent the core meaning of the concept.

Hearing aid owners and clinicians reported similar beliefs regarding the methods of hearing aid skill acquisition currently being used (Table 2). There was no significant difference between the mean rating scores each cohort provided for the concepts, with the exception of the concept "relationship with the clinician," which clinicians rated as currently used more, relative to hearing aid owners $\left[t_{(22)}=-2.0927, p<0.05\right]$.

The pattern-matching graph highlights the differences between the beliefs of hearing aid owners and clinicians regarding how beneficial each of the training concepts were (Figure 2). The clinicians' mean rating scores were significantly higher than those indicated by hearing aid owners for three concepts: "Relationship with the clinician" $\left[t_{(22)}=-2.5319, p<0.02\right]$, "clinician as a source of knowledge and support" $\left[t_{(28)}=-3.7592\right.$, $p<0.001]$, and "asking support people for help" $\left[t_{(24)}=\right.$ $-2.6437, p<0.02]$. No significant differences were observed between mean scores for the other three concepts. Both hearing aid owners and clinicians agreed that "asking support people for help" and "external resources" were significantly less beneficial than the modes of training described by the other four concepts (Table 3).
The scatterplot provides a visual representation of the individual methods of learning/training (individual statements) according to how often it is currently used in clinical practice and how beneficial it is to successful hearing aid handling and management (Figure 3). Here, rating data for each cohort are combined. More than one-third of the statements (31/75) fell within the top right quadrant, deemed to be used often and highly beneficial. These statements largely came from the concepts "clinician as a source of knowledge and support" (10/31), "relationship with the clinician" (9/31), and "hands-on experience" (9/31). Just over one-third of the statements (28/75) fell into the bottom left quadrant, deemed to be used less often and be less beneficial. Most of these statements were from the concepts "external resources" (9/28) and "asking support people for help" (12/28). Of note, all of the statements from the concept "external resources" were placed in this quadrant and all of the statements from the concept "asking support people for help," with the exception of one; statement 7 "by asking friends with hearing aids how they do things" was placed in the bottom right quadrant. Four statements (4/75) fell into the bottom right quadrant deemed to be minimally beneficial but often used. These four statements included statement 7 and statement 10 "through trial and error, 70 by trying new things if they can't do the things the clinician has instructed, for example, different ways to insert the hearing aid, and 73 reading the pamphlets supplied by the clinicians." Twelve statements (12/75) fell within

Table 2. Mean Ratings for How Often Each Method of Training Is Currently Used across Each of the Six Concepts, and the between Cohort Differences

\begin{tabular}{|c|c|c|c|c|c|}
\hline \multirow[b]{2}{*}{ Concepts } & \multirow{2}{*}{$\begin{array}{l}\text { Hearing Aid Owners } \\
\quad(\text { Mean } \pm \text { SD) }\end{array}$} & \multirow{2}{*}{$\begin{array}{c}\text { Clinicians } \\
(\text { Mean } \pm \text { SD) }\end{array}$} & \multicolumn{3}{|c|}{ Between Cohort Differences } \\
\hline & & & $t$ & Degrees of Freedom & $\overline{p \text {-value }}$ \\
\hline Relationship with the clinician & $3.26 \pm 0.38$ & $3.82 \pm 0.48$ & -2.093 & 22 & $<0.05$ \\
\hline Clinician as a source of knowledge and support & $3.22 \pm 0.42$ & $3.56 \pm 0.27$ & -1.625 & 28 & $>0.05$ \\
\hline Hands-on experience & $3.31 \pm 0.36$ & $3.33 \pm 0.26$ & -0.085 & 30 & $>0.05$ \\
\hline Seeking additional information & $2.82 \pm 0.25$ & $3.22 \pm 0.35$ & -1.626 & 18 & $>0.05$ \\
\hline Asking support people for help & $2.21 \pm 0.37$ & $2.63 \pm 0.32$ & -1.831 & 24 & $>0.05$ \\
\hline External resources & $2.11 \pm 0.21$ & $1.96 \pm 0.16$ & 0.726 & 16 & $>0.05$ \\
\hline
\end{tabular}




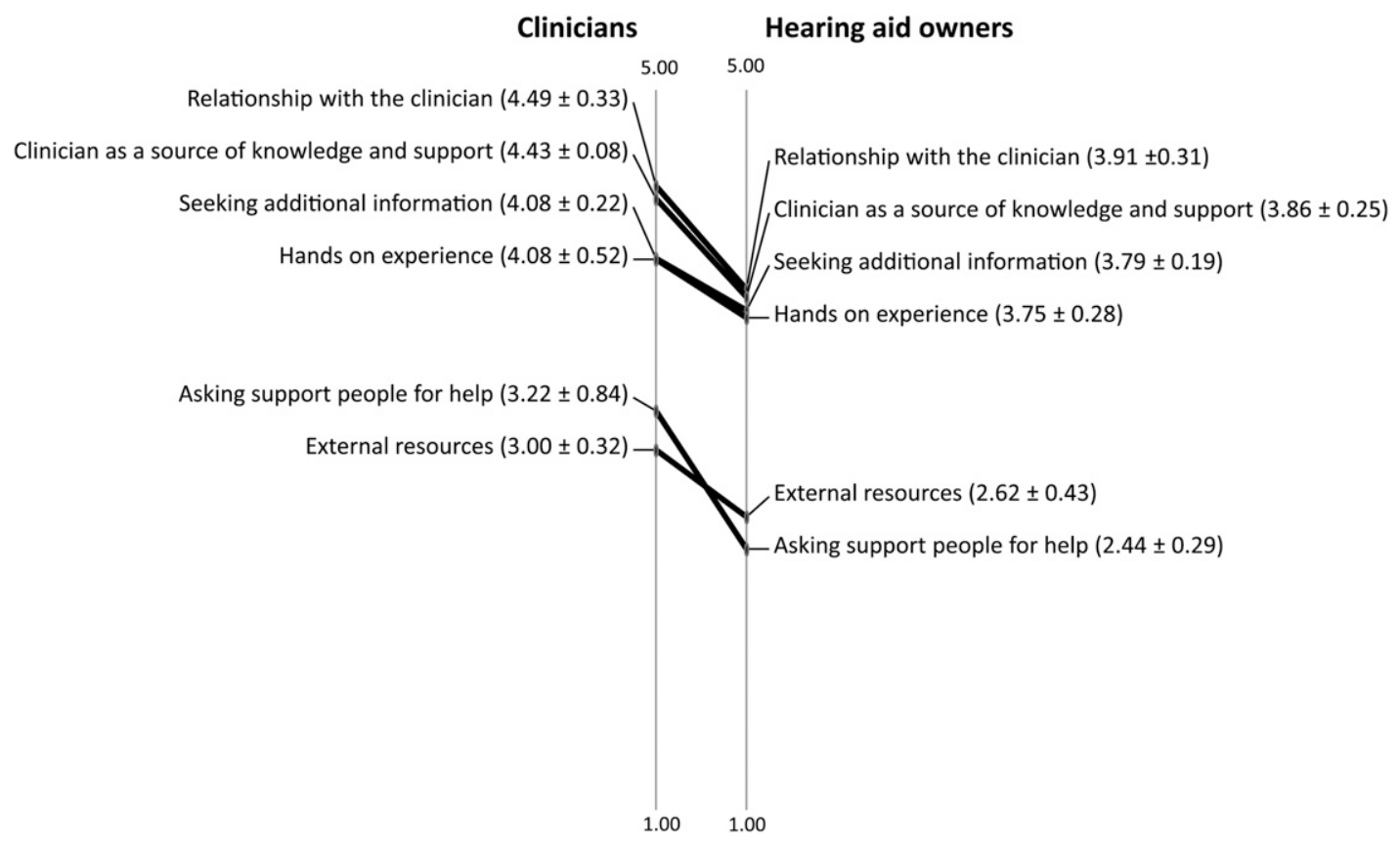

Figure 2. Pattern matching graph comparing hearing aid owners' and clinicians' ratings of how beneficial each concept describing acquisition of hearing aid skills would be to successful hearing aid management ( $1=$ minimally beneficial to $5=$ extremely beneficial). The mean cohort rating and SD for each concept is indicated in parentheses.

the top left quadrant, deemed to be beneficial but not often used. Most of these statements were from the concepts "seeking additional information" (4/12), "clinician as a source of knowledge and support" (4/12), and "hands-on experience" (3/12).

Fewer than half of the participants provided feedback ( $39 \%, \mathrm{n}=12$ hearing aid owners and $\mathrm{n}=6$ clinicians) on the final concept map generated from the participant data, as well as the names and descriptions put forward by the research team. All of the feedback supported the results and no changes were suggested.

\section{DISCUSSION}

$\mathrm{T}$ he purpose of this study was to explore the acquisition of hearing aid management skills and the effectiveness of currently used methods of hearing aid training, from the perspectives of hearing aid owners and clinicians. The 75 individual methods of skill acquisition identified in this study demonstrate the diverse players involved and the multifaceted process by which hearing aid owners learn how to use and manage their hearing aid(s).

The methods of skill acquisition deemed to be the most beneficial and currently used (based on the scatterplot) came predominantly from the three concepts describing the training provided by the clinician, the client-clinician relationship, and hands-on experience gained by the hearing aid owner. This suggests that clinicians should not only continue to use strategies that fall within these categories, but also increase their focus and utilization of them. Although, not all statements from these concepts were considered beneficial, and thus, strategies contained within each concept should be considered individually rather than applied collectively. With respect to the concept describing handson experience, rather than relying solely on traditional visual/oral delivery of hearing aid information (Kochkin et al, 2010), clinicians could look to increase the use of tactile training methods, having clients demonstrate and practice physical tasks during the clinical consultations. The benefits of such methods of training were highlighted by Singh et al (2013), who noted a reduction in the amount of time taken to complete manual hearing aid tasks (such as changing the program using a button on the hearing aid) over as few as nine task repeats. In addition, clinicians could consider emphasizing the importance of physical handling skills by setting personalized training goals with their clients, such as practicing specific tasks during the first few weeks following hearing aid fitting to consolidate learning (Lustig et al, 2009). These hands-on training methods could be complimented with written or digital supplemental materials demonstrating how to perform these tasks at home (Ferguson et al, 2015) or training sessions for significant others or carers promoting support in the home environment (Stephens, 2009; Manchaiah et al, 2012).

The two concepts, "clinician as a source of knowledge and support" and "relationship with the clinician," described the role of the hearing healthcare clinician as an individual contributing to the process of hearing 
Table 3. Comparisons between Concept Means for the Rating Data Regarding the Benefit of Each Method of Skill Acquisition, with Hearing Aid Owners and Clinician Data Measured Separately

\begin{tabular}{|c|c|c|c|c|c|c|}
\hline \multirow[b]{2}{*}{ Two Concepts Being Compared } & \multicolumn{3}{|c|}{ Hearing Aid Owners } & \multicolumn{3}{|c|}{ Clinicians } \\
\hline & $t$ & Degrees of Freedom & $\overline{p \text {-value }}$ & $t$ & Degrees of Freedom & $\overline{p \text {-value }}$ \\
\hline $\begin{array}{l}\text { Asking support people for help vs. seeking } \\
\text { additional information }\end{array}$ & 6.5880 & 21 & $<0.001$ & 2.918 & 21 & $<0.01$ \\
\hline $\begin{array}{l}\text { Asking support people for help vs. } \\
\text { hands-on experience }\end{array}$ & 6.5531 & 27 & $<0.001$ & 2.737 & 27 & $<0.02$ \\
\hline $\begin{array}{l}\text { External resources vs. seeking } \\
\text { additional information }\end{array}$ & 4.4926 & 17 & $<0.001$ & 4.489 & 17 & $<0.001$ \\
\hline External resources vs. hands-on experience & 4.4035 & 23 & $<0.001$ & 4.141 & 23 & $<0.001$ \\
\hline
\end{tabular}

aid skill acquisition. The statements within these concepts described the process of finding the right clinician and developing a relationship with that clinician. The importance of developing the therapeutic relationship between the client and clinician indicated in this study echoes previous qualitative research exploring the process involved in and the benefits of a patient-centered approach to care (Laplante-Lévesque et al, 2010b; Poost-Foroosh et al, 2011; Grenness et al, 2014). The process of imparting hearing aid related knowledge and providing training and support during clinical appointments facilitates development of the client-clinician relationship through the opportunity for the client to evaluate the clinician's individual working style and to determine the extent to which the clinician's attitudes and behaviors match the client's own preferences and expectations (Poost-Foroosh et al, 2015). However, it appears that hearing aid owners' preferences for the amount of information and the level of detail or technicality they wish to receive may differ between individuals. When asked to describe problems associated with hearing aid use, participants identified problems associated with clinicians' current methods of hearing aid education and training, which included the provision of insufficient as well as excessive or overly complex information (Bennett et al, 2018a). Although it is not surprising that individual patients will prefer different amounts of information, these results suggest the need for a patient-centered approach to care. Improvements may be noted when clinicians personalize

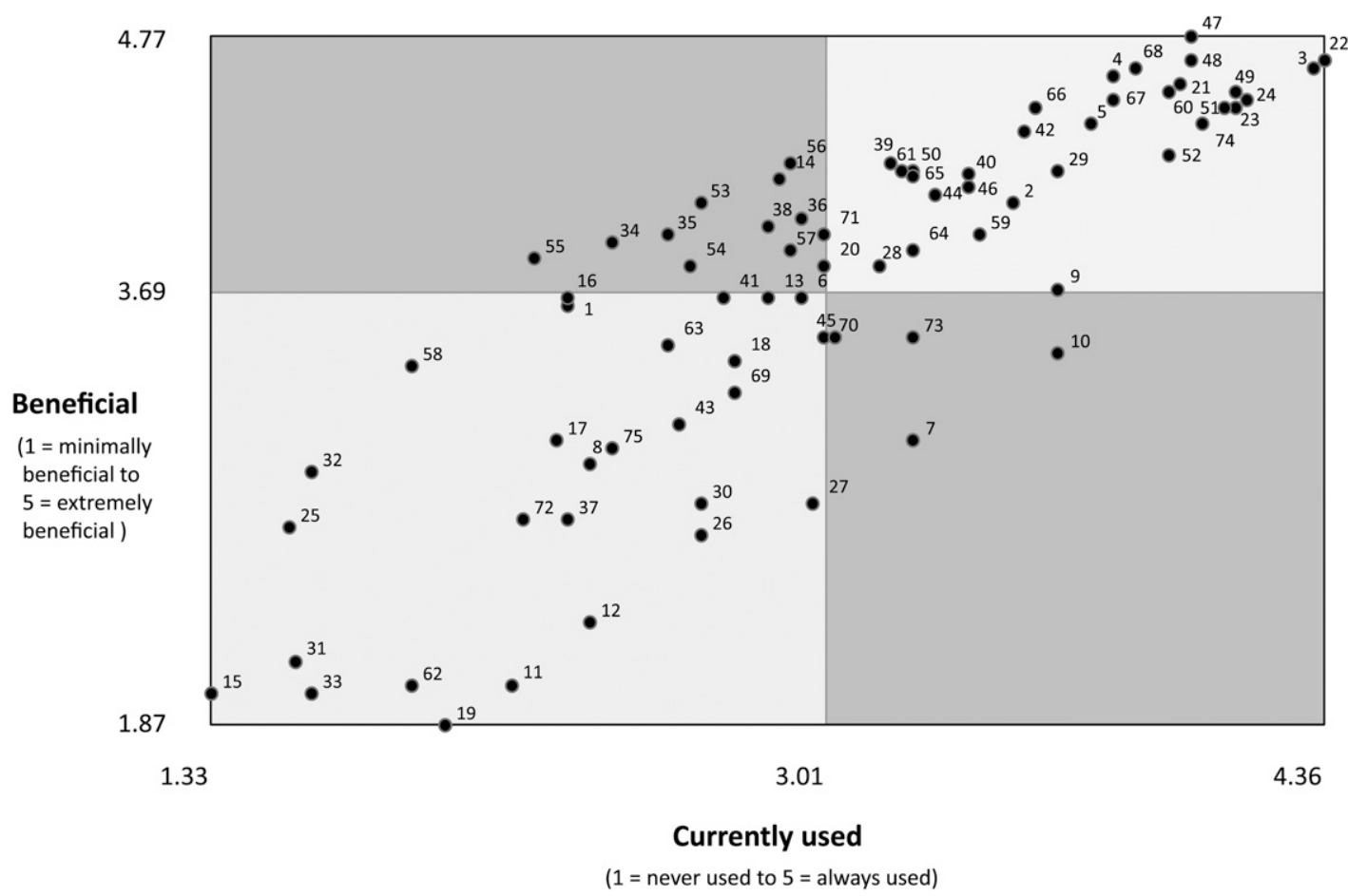

Figure 3. Scatterplot of participants' ratings of how often each learning/training technique is currently used against how beneficial it is to successful hearing aid handling and maintenance for all statements. 
the appointment and ask each individual client how much information they would like at each session, how much technical detail they would prefer, and how they would like to receive this information (such as verbally, written, and pictorial). Doing so will likely further enhance the client-clinician relationship and improve the process of information transfer from clinician to client.

Clinicians in this study rated the concept "relationship with the clinician" as more important to skill acquisition than the hearing aid owners rated it. These findings are consistent with Laplante-Lévesque et al (2013), wherein clinicians emphasized the role of the client-clinician relationship as a determinant of hearing aid use, whereas hearing aid owners emphasized the role of the hearing aid in achieving optimal hearing aid use. It is possible that hearing aid owners are unaware of the role that the clinician can play in the process of aural rehabilitation. This is likely because of current clinical practices placing greater emphasis on the hearing aid than on the services provided by the clinician during consultations. This emphasis on the hearing aid could be remnant of the historical dominance of a medical approach to health care used in audiology (Erdman et al, 1994). Although audiological practices are moving toward a biopsychosocial approach to audiological rehabilitation, with consideration given to the activity limitations and participation restrictions that affect people with hearing impairment and their significant others (Hickson and Scarinci, 2007; Meyer et al, 2016), some suggest that the current pricing structures for audiological rehabilitation, charging a bundled fee for hearing aids and services, keep the focus on the hearing aid device and underrepresent the role of the clinician (Shaw, 2015). There is growing support for the unbundling of hearing aid sales and services to allow for reimbursement of individual aspects of the rehabilitation program, such as counseling on social reintegration and hearing aid management training (Shaw, 2015). Highlighting hearing aid training as a separate and billable feature of the rehabilitation program emphasizes its value and necessity and may help to address the low handling skills evidenced in clinical studies (Bertoli et al, 2009; Desjardins and Doherty, 2009; Ferrari et al, 2015; Bennett et al, 2017a).

The individual statements deemed to be commonly used, although not beneficial included the use of trialand-error techniques to develop hearing aid skills and reading the pamphlets provided by the hearing clinic. It is possible that hearing aid owners reap little benefit from engaging in trial-and-error techniques due to a lack of basic skills regarding hearing aid handling and low confidence regarding their ability to manage the device (West and Smith, 2007; Desjardins and Doherty, 2009; Bennett et al, 2017a). Placing greater emphasis on hearing aid management training during clinical consultations will provide hearing aid owners with the skills required to self-manage their condition. This may be achieved through use of clinical tools identifying deficiencies in handling skills, such as the Practical Hearing Aid Skills Test (Desjardins and Doherty, 2009). With respect to pamphlets provided by the hearing clinic, it is not surprising that participants in this study derive little benefit from them as studies report the low quality and poor readability of hearing aid user manuals (Caposecco et al, 2014), and highlight the high level of health literacy required to understand the content of written information concerning hearing aids provided during clinical consultations (Nair and Cienkowski, 2010; Brooke et al, 2012). These factors compound to result in hearing aid owners often misinterpreting the information provided. To overcome these shortfalls, clinicians could call on hearing aid manufacturers to improve their user manuals or develop their own materials. Client recall of health information can be enhanced through organization of the information provided, use of less complex text, larger typeface sizes, and the use of pictures (Ley et al, 1973; Kools et al, 2006; Caposecco et al, 2016). For example, Caposecco et al (2016) demonstrated improved hearing aid management skills, the need for fewer prompts and faster task completion when hearing aid user manuals were modified, including a lower reading grade level.

The individual methods of skill acquisition put forward by participants indicated the involvement of many people, including the hearing aid owners, the clinician, and clinic administration staff, family members, friends with hearing aids, general practitioners, as well as nursing home staff and carers. However, the rating data generated by participants suggest that the support sourced from parties external to the clinic are less beneficial, with the individual statements describing these sources as being of less quality, inaccurate or more difficult to access than that provided by the clinician. Clinicians need to be cognizant of this and consider involving these many potential support people in the process of hearing aid training, either directly (such as encouraging hearing aid owners to bring a family member to appointments or sending hearing aid specific information to carers and nursing home staff) (Manchaiah et al, 2012) or indirectly (by providing general hearing aid related training to general practitioners and the general public) (Gilliver and Hickson, 2011). The benefits of involving significant others in the process of aural rehabilitation are well demonstrated (Preminger, 2003; Preminger and Meeks, 2010; Hickson et al, 2014; Singh et al, 2015) and support the use of a family-centered approach to care (Singh et al, 2016). To facilitate a family-centered approach to hearing aid skill acquisition a clinician could (a) invite family members to attend hearing aid training appointments, (b) set up the physical environment so that family 
members are comfortably involved in the hearing aid orientation and training, such as ensuring that family members and the hearing aid owner both understand the information provided, and have a turn practicing the physical tasks required for hearing aid management, and (c) setting joint hearing aid-related goals with the hearing aid owner and the family member(s) present, such as how and when to use the hearing aid.

\section{Limitations and Future Directions}

One of the limitations of this study was that participants self-selected to volunteer for the study, which may have biased the content and the rating scales. The sample sizes were within the recommended numbers for concept mapping studies; however, the small numbers may have influenced the ratings of the statements provided. In addition, other hearing aid owners and clinicians may have generated additional statements not included in this study. Nevertheless, the number of statements generated was large and this is the most comprehensive study to date looking at how hearing aid management skills and knowledge is acquired. Given the sample size, the rating scale results should not be assumed representative of the population. Future research could explore whether the use of information sources differ across sub groups of hearing aid owners, such as those with greater hearing aid satisfaction, those in rural or remote areas or those with language barriers. Only $35 \%$ of participants provided feedback on the final concept map generated from the data. Nonetheless, findings are informative and provide a framework for improving the delivery of hearing aid management training.

\section{CONCLUSION}

$\mathrm{T}$ he purpose of this study was to explore the acquisition of hearing aid management skills and the effectiveness of currently used methods of hearing aid training, from the perspectives of hearing aid owners and clinicians. The results of this study demonstrate the diverse methods and sources by which hearing aid owners learn the skills necessary to use, manage, and maintain their hearing aids. Clinicians may enhance hearing aid owners' acquisition of skills by further diversifying the methods of skill training used to include (a) use of personalized training programs, (b) opportunity to learn, demonstrate and practice physical techniques during appointments, (c) use of written, pictorial, or digital supplemental materials to support learning, and (d) greater client empowerment throughout the hearing aid fitting process. Significant emphasis was placed on the role of the hearing health clinician to provide training, support, and an ongoing professional relationship, with lesser roles played by family, friends, and other health professionals. The adoption of a family-centered approach to client care would enable the inclusion of the wide variety of players involved in an individual's aural rehabilitation, dually resulting in improved outcomes for the hearing aid owners and their family.

Acknowledgments. The authors would like to acknowledge the assistance of Unitron Australia, the Lions Hearing Clinic, and the Communication Research Registry with participant recruitment and the participants for devoting their time to this study.

\section{REFERENCES}

American Speech-Language-Hearing Association. (2015) Hearing aids for adults. http://www.asha.org/PRPSpecificTopic.aspx? folderid $=8589935381 \&$ section $=$ Overview. Accessed June 2016 .

Audiology Australia. (2013) Audiology Australia professional practice standards-Part B clinical standards. http://www.audiology. asn.au/standards-downloads/Clinical\%20Standards $\% 20-\%$ 20whole\%20document\%20July $13 \% 201$.pdf. Accessed October 2015.

Bennett RJ, Meyer C, Eikelboom RH. (2016) Does clinician continuity influence hearing aid outcomes? Int J Audiol 55(10): $556-563$.

Bennett RJ, Meyer C, Taljaard DS, Eikelboom RH. (2017a) Are hearing aid owners able to identify and self-report handling difficulties? A pilot study. Int J Audiol 56(11):887-893.

Bennett RJ, Laplante-Levesque A, Meyer CJ, Eikelboom RH. (2018a) Exploring hearing aid problems: perspectives of hearing aid owners and clinicians. Ear Hear 39(1):172-187.

Bennett RJ, Meyer CJ, Eikelboom RH, Atlas MD. (2018b) Investigating the knowledge, skills and tasks required for hearing aid management: perspectives of clinicians and hearing aid owners. Am J Audiol 27:67-84.

Bertoli S, Staehelin K, Zemp E, Schindler C, Bodmer D, Probst R. (2009) Survey on hearing aid use and satisfaction in Switzerland and their determinants. Int $J$ Audiol 48(4):183-195.

Brooke RE, Isherwood S, Herbert NC, Raynor DK, Knapp P. (2012) Hearing aid instruction booklets: employing usability testing to determine effectiveness. Am J Audiol 21(2):206-214.

Campos PD, Bozza A, Ferrari DV. (2014) Hearing aid handling skills: Relationship with satisfaction and benefit. Codas 26(1): 10-16.

Caposecco A, Hickson L, Meyer C. (2014) Hearing aid user guides: Suitability for older adults. Int J Audiol 53(1, Suppl):S43-S51.

Caposecco A, Hickson L, Meyer C, Khan A. (2016) Evaluation of a modified user guide for hearing aid management. Ear Hear 37(1):27-37.

Chisolm TH, Johnson CE, Danhauer JL, Portz LJ, Abrams HB, Lesner S, Newman CW. (2007) A systematic review of health-related quality of life and hearing aids: final report of the American Academy of Audiology Task Force on the healthrelated quality of life benefits of amplification in adults. J Am Acad Audiol 18:(2):151-183. 
Concept Systems Incorporated. (2011) The Concept System [Computer Software], Version 4, Ithaca, NY. http://www.conceptsystems.com.

Desjardins JL, Doherty KA. (2009) Do experienced hearing aid users know how to use their hearing AIDS correctly? Am J Audiol 18(1):69-76.

El-Molla F, Smith Z, Henshaw H, Ferguson M. (2012) Retention of rehabilitation information by first-time hearing aid users with and without interactive patient information.Paper presented at the meeting of the British Academy of Audiology. Manchester, UK.

English K. (2008) Counseling issues in audiologic rehabilitation. Contemp Issues Commun Sci 35:93-101.

Erdman SA, Wark DJ, Montano JJ. (1994) Implications of service delivery models in audiology. J Acad Rehabil Audiol 27:45-60.

Ferguson M, Brandreth M, Brassington W, Wharrad H. (2015) Information retention and overload in first-time hearing aid users: an interactive multimedia educational solution. Am J Audiol 24(3):329-332.

Ferrari DV, Jokura PR, Silvestre NA, Campos PD, Paiva PMP. (2015) Practical hearing aid skills test: results at the time of fitting and comparison of inter-rater reliability. Audiol Commun Res 20(2):110-115.

Gilliver M, Hickson L. (2011) Medical practitioners' attitudes to hearing rehabilitation for older adults. Int J Audiol 50(12):850-856.

Grenness C, Hickson L, Laplante-Levesque A, Davidson B. (2014) Patient-centred audiological rehabilitation: perspectives of older adults who own hearing aids. Int J Audiol 53(Suppl): S68-S75.

Hickson L, Scarinci N. (2007) Older adults with acquired hearing impairment: applying the ICF in rehabilitation. Semin Speech Lang 28(4):283-290.

Hickson L, Meyer C, Lovelock K, Lampert M, Khan A. (2014) Factors associated with success with hearing aids in older adults. Int $J$ Audiol 53(Suppl):S18-S27.

Hinkle DE, Wiersma W, Jurs SG. (2003) Applied statistics for the behavioral sciences. J Educ Stat 15(1):84-87.

Jackson KM, Trochim WM. (2002) Concept mapping as an alternative approach for the analysis of open-ended survey responses. Organ Res Methods 5:307-336.

Kane M, Trochim WM. (2007) Concept Mapping for Planning and Evaluation Vol. 50. Thousand Oaks, CA: Sage.

Kelly TB, Tolson D, Day T, McColgan G, Kroll T, Maclaren W. (2013) Older people's views on what they need to successfully adjust to life with a hearing aid. Health Soc Care Community 21(3):293-302.

Kochkin S, Beck DL, Christensen LA, Compton-Conley C, Fligor BJ, Kricos PB, McSpaden JB, Gustav Mueller H, Nilsson MJ, Northern JL, Powers TA, Sweetow RW, Taylor B, Turner RG. (2010) MarkeTrak VIII: the impact of the hearing healthcare professional on hearing aid user success. Hear Rev 17(4):12-34.

Kools M, van de Wiel MW, Ruiter RA, Kok G. (2006) Pictures and text in instructions for medical devices: effects on recall and actual performance. Patient Educ Couns 64(1):104-111.

Kumar M, Hickey S, Shaw S. (2000) Manual dexterity and successful hearing aid use. J Laryngol Otol 114(8):593-597.
Laplante-Lévesque A, Hickson L, Worrall L. (2010a) Promoting the participation of adults with acquired hearing impairment in their rehabilitation. J Acad Rehabil Audiol 43:11-26.

Laplante-Lévesque A, Hickson L, Worrall L. (2010b) A qualitative study of shared decision making in rehabilitative audiology. $J$ Acad Rehabil Audiol 43:27-43.

Laplante-Lévesque A, Jensen LD, Dawes P, Nielsen C. (2013) Optimal hearing aid use: focus groups with hearing aid clients and audiologists. Ear Hear 34(2):193-202.

Ley P, Bradshaw P, Eaves D, Walker C. (1973) A method for increasing patients' recall of information presented by doctors. Psychol Med 3(2):217-220.

Lilien GL, Rangaswamy A. (2004) Marketing Engineering: ComputerAssisted Marketing Analysis and Planning. Revised 2nd ed. Victoria, Canada: Trafford Publishing.

Lustig C, Shah P, Seidler R, Reuter-Lorenz PA. (2009) Aging, training, and the brain: a review and future directions. Neuropsychol Rev 19(4):504-522.

Manchaiah VK, Stephens D, Zhao F, Kramer SE. (2012) The role of communication partners in the audiological enablement/ rehabilitation of a person with hearing impairment: an overview. Audiological Med 10(1):21-30.

Meyer C, Grenness C, Scarinci N, Hickson L. (2016) What is the international classification of functioning, disability and health and why is it relevant to audiology? Semin Hear 37(3): $163-186$

Nair EL, Cienkowski KM. (2010) The impact of health literacy on patient understanding of counseling and education materials. Int J Audiol 49(2):71-75.

Poost-Foroosh L, Jennings MB, Cheesman MF. (2015) Comparisons of client and clinician views of the importance of factors in client-clinician interaction in hearing aid purchase decisions. $J$ Am Acad Audiol 26(3):247-259.

Poost-Foroosh L, Jennings MB, Shaw L, Meston CN, Cheesman MF. (2011) Factors in client-clinician interaction that influence hearing aid adoption. Trends Amplification 15(3): $127-139$

Preminger JE. (2003) Should significant others be encouraged to join adult group audiologic rehabilitation classes? J Am Acad Audiol 14(10):545-555.

Preminger JE, Meeks S. (2010) Evaluation of an audiological rehabilitation program for spouses of people with hearing loss. $J \mathrm{Am}$ Acad Audiol 21(5):315-328.

Reese JL, Hnath-Chisolm T. (2005) Recognition of hearing aid orientation content by first-time users. Am J Audiol 14(1):94-104.

Rosas SR, Kane M. (2012) Quality and rigor of the concept mapping methodology: a pooled study analysis. Eval Program Plann $35(2): 236-245$.

Shaw G. (2015) Unbundling hearing healthcare pricing: up-front work pays off. Hear $J$ 68(9):28-30.

Singh G, Hickson L, English K, Scherpiet S, Lemke U, Timmer B, Launer S. (2016) Family-centered adult audiologic care: a phonak position statement. Hear Rev 23(4):16.

Singh G, Lau ST, Pichora-Fuller MK. (2015) Social support predicts hearing aid satisfaction. Ear Hear 36(6):664-676. 
Singh G, Pichora-Fuller K, Hayes D, von Schroeder HP, Carnahan H. (2013) The aging hand and the ergonomics of hearing aid controls. Ear Hear 34(1):e1-e13.

Solheim J, Kvaerner KJ, Falkenberg ES. (2011) Daily life consequences of hearing loss in the elderly. Disabil Rehabil 33(23-24):2179-2185.

Stephens D. (2009) Living with Hearing Difficulties: The Process of Enablement. Chichester, West Sussex, UK: John Wiley \& Sons.

Trochim W. (1993) The reliability of concept mapping. Paper presented at the Annual Conference of the American Evaluation Association, Dallas, TX, November 6, 1993.
Trochim WM. (1989) An introduction to concept mapping for planning and evaluation. Eval Program Plann 12(1):1-16.

Upfold L, May A, Battaglia J. (1990) Hearing aid manipulation skills in an elderly population: a comparison of ITE, BTE, and ITC aids. Br J Audiol 24(5):311-318.

Wedel M, Kamakura WA. (2000) Market Segmentation: Conceptual and Methodological Foundations. 2nd ed. Boston, MA: Kluwer Academic Press.

West RL, Smith SL. (2007) Development of a hearing aid selfefficacy questionnaire. Int J Audiol 46(12):759-771. 


\section{APPENDIX}

Statements grouped by key concepts, with bridging score indicated in brackets for each statement and concept. The bridging scores for each statement indicate how often participants grouped these statements together (i.e., placed them in this concept), with a lower score indicating that participants more often grouped these statements together.

\section{External Resources (0.62)}

1. Participating in research projects involving hearing aids (0.77)

15. Going to the library and borrowing a book on hearing aid selection, use, and management (0.59)

17. Through the quarterly/annual clinic newsletters they receive offering tips/information on hearing and hearing aids (0.54)

25. Watching YouTube videos (0.66)

37. Reading the posters on the clinic waiting room wall that describe hearing aid tips (0.57)

58. Viewing videos that demonstrate/explain the different skills they need to use hearing aids, available on some clinic websites $(0.55)$

62. Searching general websites (0.61)

72. Visiting an electronics store to ask about or purchase headphones for the TV (0.70)

75. Reading the coffee table literature on hearing aid use in the clinic waiting room (0.57)

\section{Hands-on Experience (0.49)}

2. Reading the user manual (0.43)

9. Through practical experience, just trying things themselves when problems arise (0.42)

10. Through trial and error (0.46)

21. Taking time to familiarise themselves with the hearing aid at the fitting appointment $(0.62)$

22. Through practice $(0.44)$

26. Making assumptions based on the contents of the box, that is, working out what each item is used for $(0.51)$

27. Working it out for themselves (0.42)

35. Learning how to learn the new skills $(0.61)$

38. Practising all aspects of hearing aid use several times per day during those first few days/weeks $(0.42)$

39. Making time to practice at home while in a relaxed environment (0.41)

40. Prioritising the magnitude of information/instructions provided and only focusing on the basic and necessary instructions at first (0.60)

44. Reading the personalised hearing aid instructions printed from the hearing aid fitting software, if provided (0.46)

47. Being self-motivated (0.52)

50. Using troubleshooting guides, as it can be both helpful and empowering to be able to solve their own problems (0.47)

54. Putting hearing instructions somewhere obvious at home, allowing daily reminders of what and how to do the important tasks (0.50)

70. Trying new things if they can't do the things the clinician has instructed, for example, different ways to insert the hearing aid (0.61) 


\section{Asking Support People for Help (0.66)}

6. Starting at a younger age, that is, it is easier to learn new things when you are younger (1.00)

7. Asking friends with hearing aids how they do things (0.59)

11. Asking nursing staff (both in general hospitals and care facilities), although they usually don't know how to help (0.43)

12. Asking family members to do it for them (0.55)

13. Getting family members to come to appointments so that they can learn how to assist (0.69)

18. Asking their carer to learn the necessary skills, so that they can then rely on them if need be $(0.65)$

19. Asking their General Practitioner (family doctor) (0.58)

30. Talking to friends $(0.48)$

31. Calling the office of hearing services helpline (0.69)

32. Talking to specialists regarding memory issues that may be interfering with learning hearing aid handling skills (0.95)

33. Asking the social worker who visits the house (0.72)

41. Asking partners and/or family members to attend appointments (0.56)

69. Through helping other people experiencing difficulties with their hearing aids (0.75)

\section{Clinician as a Source of Knowledge (0.18)}

3. Listening to the things their clinician says $(0.11)$

4. Going back to their clinician and asking more questions $(0.12)$

14. Asking their clinician to summarise the important tasks on a cheat sheet, that is, a simple overview of the more common hearing aid instructions (0.29)

28. Watching what the clinician does when cleaning/fixing the hearing aid and to do the same at home $(0.34)$

29. Asking the clinician how to perform certain tasks, for example, how to change the speaker/wax filter (0.18)

45. Watching the clinician put a similar style hearing aid in and out of their ear to demonstrate (0.15)

46. Attending several appointments over the fitting process rather than one large appointment, as too much information in one chunk can be difficult to remember $(0.22)$

52. Attending annual (or more frequent) check-up appointments $(0.31)$

55. Discussing their learning style with their clinician so that the clinician can teach/instruct in this way, for example, visual learner, auditory learner, etc. (0.10)

57. Repeating key instructions back to the clinician to ensure they have been heard, interpreted, and remembered correctly (0.17)

59. Discussing their motivations or hesitations for getting hearing aids in the first place with their clinician $(0.17)$

61. Completing hearing aid management evaluation in the follow-up appointment, that is, where the clinician assesses the hearing aid owner's ability to perform necessary skills and then provide retraining where required $(0.16)$

68. Knowing that they have someone to go to with questions, that is, the clinician (0.05)

71. Know to ask the clinician to simplify the hearing aid, for example, ensure the same battery size for each hearing aid, asking for moulds instead of domes (0.15)

74. Following the clinicians advice $(0.19)$ 


\section{Relationship with the Clinician (0.14)}

5. Through developing a relationship with their clinician $(0.00)$

8. Getting a second opinion from another clinician (0.28)

23. With encouragement from their clinician (0.01)

24. With encouragement and assurance from their clinician that they will be able to manage the hearing aid with practice $(0.01)$

43. Asking the receptionist to go through aspects of hearing aid management that they may be having difficulty, outside of appointments $(0.72)$

48. Being made to feel like an important part of the rehabilitation (hearing aid fitting) process, where the clinician makes it clear that the hearing aid owner is welcome to ask questions and take their time (0.01)

49. Being informed at the beginning that learning to use hearing aids takes time and that it is normal to return for follow-up appointments for re-training (0.27)

51. Having a good relationship with their clinician, especially open lines of communication to be able to ask for support (0.00)

53. Discussing memory concerns with their clinician, allowing the clinician to tailor the rehabilitation program for their personal needs $(0.29)$

65. Finding a clinician who is aware of the hearing aid owner's overall health and how it relates to using hearing aids $(0.01)$

66. Finding a clinician who is open and happy to talk/discuss everything (0.01)

67. Developing a good relationship with their clinician (0.01)

\section{Seeking Additional Information (0.56)}

16. Asking for print outs of the information (0.53)

20. Holding and testing different styles of hearing aids at the first appointment to check comfort, ease of use, and potential ability to manage batteries/style/care of device (0.59)

34. Repeatedly asking questions until they get an answer that makes sense to them (0.52)

36. Repeatedly asking questions until the problem is resolved (0.53)

42. Instead of watching the clinician's demonstration of how to care for the hearing aid, giving it a try under the clinician's supervision (0.47)

56. Engaging in an ongoing rehabilitation program that allows them to gradually build upon their skills is a supportive and timely manner, where appointments are scheduled to meet their personal needs $(0.44)$

60. Understanding why cleaning and other management tasks are necessary, for example, they will prevent breakdowns (0.57)

63. Using the diagrams provided by their clinician for specific tasks, for example, how to cut the tube on a new mould to the correct length $(0.63)$

64. Reading the sections of the instruction booklet that the clinician has highlighted as relevant to their own personal hearing aids $(0.68)$

73. Reading the pamphlets supplied by the clinician $(0.61)$ 